\title{
The relationship between barriers to change and the work engagement of employees in a South African property management company
}

\author{
Authors: \\ Elsabé Bell ${ }^{1}$ \\ Nicolene Barkhuizen ${ }^{1}$ \\ Affiliations: \\ ${ }^{1}$ Department of Industrial \\ Psychology and People \\ Management, University of \\ Johannesburg, South Africa \\ Correspondence to: \\ Nicolene Barkhuizen \\ Email: \\ nicolene.barkhuizen@up.ac.za \\ Postal address: \\ PO Box 524, Auckland Park \\ 2006, South Africa \\ Dates: \\ Received: 31 Aug. 2010 \\ Accepted: 16 May 2011 \\ Published: 29 Sept. 2011 \\ How to cite this article: \\ Bell, E., \& Barkhuizen, N. \\ (2011). The relationship \\ between barriers to change \\ and the work engagement of \\ employees in a South African \\ property management \\ company. SA Journal of \\ Industrial Psychology/SA \\ Tydskrif vir Bedryfsielkunde, \\ 37(1), Art. \#935, 11 pages. \\ doi:10.4102/sajip.v37i1.935 \\ Note: \\ This article is part of a \\ master's research study \\ by the first author, Elsabé \\ Bell, at the Department \\ of Industrial Psychology \\ and People Management, \\ University of Johannesburg. \\ Dr Barkhuizen was the study \\ leader of the research at the \\ institution.
}

C 2011. The Authors.

Licensee: AOSIS

OpenJournals. This work

is licensed under the

Creative Commons

Attribution License.
Orientation: For any organisational change initiative to have a successful outcome, people need to contribute and be engaged in the process.

Research purpose: The main objective of the research was to determine the relationship between barriers to change and work engagement. The secondary objectives of the research were to determine whether there are significant relationships between barriers to change, work engagement and demographic variables.

Motivation for the study: Exploring and understanding the relationship between barriers to change and work engagement amongst different demographic groups will help organisations to predict which working environments and jobs are amenable to organisational change and which will alleviate, and maybe even eliminate, the negative effects of change.

Research design, approach and method: The researchers used a cross-sectional survey research design. They drew a convenience sample of 234 employees $(N=234)$ from a South African property management company. They administered the Barriers to Change Questionnaire and the Utrecht Work Engagement Scale.

Main findings: The results showed a practically significant relationship, with a large effect, between barriers to change and work engagement. In addition, the results showed significant differences between barriers to change and demographic groupings based on home language, ethnicity and organisational level. The results also showed significant differences between work engagement and demographic groupings based on home language, ethnicity and level of education.

Practical/managerial implications: Managing barriers to change can increase the work engagement of employees.

Contribution/value-add: The research adds to the knowledge about the adverse effects of organisational change initiatives on people.

\section{Introduction}

Organisations have to survive in an environment, which increased global competition, customers as their focal point, an ongoing need for innovation, a drive to retain key talent and improved cost-effectiveness, characterises (Mason, 2008; Soltani, Lai \& Mahmoudi, 2007).

The pace of change is spiralling out of control. Organisations are restructuring. There are ongoing technological revolutions, market changes, higher levels of unemployment, deregulation, mergers and acquisitions, the empowerment of consumers and changes in demand patterns. All of these create additional pressures in the working environment. Therefore, it is imperative that organisations constantly introduce changes in strategy, structure, processes and culture to maintain their competitive advantage (Higgs, 2002).

Challenges to, and changes in, property management organisations have caused, amongst others, restructuring, downsizing, multitasking and retrenchments (US Industry Report, 2011). They often cite change management practices as a reason for resisting change because it causes job insecurity, increased stress, the loss of competent and engaged employees and increased workloads (Goleman, Boyatzis \& McKee, 2002; Rees, 1997). 
Effective change management is imperative because barriers to change are evident in all changing environments and manifest in resistance to change (Coetzee \& Stanz, 2007). Coetzee and Stanz state that one can define barriers to change as the obstacles that hinder change and cause resistance. Employee resistance can be a significant obstacle to effective organisational change because it can generate scepticism and resistance in employees. They make it difficult for organisations to improve (Schumacher, 2003 cited in Coetzee, 2006). Change clearly affects the operation of systems and processes. It also affects the people in this environment. It affects how they think and behave, their perceptions, their ability to handle the changing environment and their engagement (Ndlovu \& Parumasur, 2005).

Engagement is a social process through which leaders and employees become personally involved in the performance of their teams by contributing to wider organisational change, strategy and transformation (Smythe, 2005). Change commitment refers to the positive attitudes about the change, the alignment to change, the intention to support it and the willingness to work toward its successful implementation (Herold, Fedor \& Caldwell, cited in Van Emmerik, Bakker \& Euwema, 2009).

Without engaged and committed employees, change initiatives cannot succeed.

Our current understanding of barriers to change and their relationship with work engagement is limited because most research tends to concentrate on management and resistance to change, the effects of change and reactions to it (Coetzee \& Stanz, 2007).

Exploring and understanding the relationship between barriers to change and work engagement will help organisations to predict which working environments and jobs are amenable to organisational change and which will alleviate, or perhaps even eliminate, the negative effects of change (Coetzee, 2006; Van Emmerik et al., 2009).

If organisations are aware of the barriers to change, it means that employees will be more likely to engage rather than disengage during the process of change and increase the possibility of successful outcomes.

Therefore, the main objective of this research is to determine whether there is a significant relationship between barriers to change and work engagement. The research will also determine whether there are significant differences between barriers to change, work engagement and the demographic characteristics of the participants.

\section{Literature review}

\section{Change management, resistance to change and barriers to change}

Markets are becoming more global, deregulated and competitive. Therefore, change initiative programmes, as the key tools for long-term organisational success, are becoming more common (Soltani et al., 2007).
Although change is important for organisations to survive, it causes them to destabilise. Therefore, it is important to make change a management issue (Coetzee \& Stanz, 2007; Lombard \& Crafford, 2003).

This emerged from research on managing change that The Institute of Corporate Productivity (2008) conducted. It involved 132 organisations worldwide.

The results of this study showed that change management initiatives in organisations are increasing rapidly, that organisations are struggling with the pace of change, that perceived satisfaction with leadership is most often the basis of successful change initiatives and that the responsibility for managing change tends to be at top levels (The Institute of Corporate Productivity, 2008).

However, Isern and Pung (2007), in a study of 1536 executives, found that only $38 \%$ of the participants thought that change initiatives were successful and that only $30 \%$ thought they contributed to the sustained improvement of their organisations. Resistance to change is recognised as a main reason for difficulties in implementing organisational change efforts and for their failure (Harich, 2010; MsweliMbanga \& Potwana, 2006; Oreg, 2006; Williams, Crafford \& Fourie, 2003).

Resistance is any opposition to a shift in the status quo. This means 'to slow down a process' or to 'put obstacles in the way of goal achievement' (Mariotti, cited in Lombard \& Crafford, 2003). Although the cause of this resistance may be the individual, Kotter (cited in Harrich, in press) found that one is most likely to find it 'elsewhere' in the system.

Research has shown that several factors influence people's attitudes and resistance to change. These are communicating change, the level of managers' understanding of the change, the consistency of managers' actions about the goals of the change initiative and participation in the process of change (see Coetzee \& Stanz, 2007; Msweli-Mbanga \& Potwana, 2006; Oreg, 2006; Lombard \& Crafford, 2003).

Organisational systems share the characteristics of homeostasis with human systems. These, according to Lewin (cited in Harrich, 2010), can occur in an equilibrium between the barriers to change and the forces that favour change. Lewin maintains that an imbalance between these two forces (i.e. a weakening of the barriers or a strengthening of the driving forces) is necessary to begin the change. Therefore, the barriers to change embody resistance to change (Mariotti, cited in Coetzee \& Stanz, 2007).

Schumacher (cited in Coetzee, 2006) refers to barriers in a project as severe, unexpected and unplanned. Barriers can hinder implementation efforts to such an extent that, without intervention, the change project may falter or fail. According to Schumacher (cited in Coetzee and Stanz, 2007), one can categorise barriers to change as project-related barriers, people-related barriers, organisation-related barriers and environment-related barriers. 
Project-related barriers are those that are inherent in the change initiative, the change process and the management of the project. They include dimensions like direction, clarity or uncertainty and planning, implementing and controlling the project.

People-related barriers refer to resistance from both staff and managers. Satisfaction with the status quo, resistance to change itself, change fatigue, inadequate leadership or management, uncertainty, fear, competitive commitments, people-related barriers and personality conflicts may cause them.

Organisational barriers can include organisation structure, systems, procedural and system barriers, organisational culture and climate, previously failed change efforts, insufficient resources and an inability to change.

Environmental barriers can come from customers, suppliers and partners.

This categorisation of the barriers to change gives a holistic view of the obstacles that organisations can experience whilst changing. Coetzee and Stanz (2007) maintain that the real issue is that managers do not understand what these barriers are and where they manifest in the organisation.

Therefore, it is critical for organisations to form a holistic view of the barriers to change, identify the barriers and then plan to remove them. Research has found that the conditions of change can be the antecedents of resistance. These, in turn, predict outcomes like job satisfaction, organisational commitment and turnover (Schweiger \& De Nisi, cited in Oreg, 2006).

In addition, Oreg (2006) states that the conditions in which specific changes occur may influence employees' attitudes to the changes. These, in turn, could affect their general attitude towards organisations.

It is in this context that the researchers investigated the effect of barriers to change on work engagement, as Stanz and Coetzee (2007) define it.

\section{Work engagement}

For purposes of this research, work engagement is a 'positive, fulfilling, affective-motivational state of work-related wellbeing' that vigour, dedication and absorption typify (Bakker, Schaufeli, Leiter \& Taris, 2008; Schaufeli \& Bakker, 2001, 2003).

High levels of energy and mental resilience whilst working, the willingness to invest effort in one's work and persistence in the face of difficulties are the characteristics of vigour. A sense of significance, enthusiasm, inspiration, pride and challenge typify dedication. Finally, being totally and happily immersed in one's work, to the extent that it is difficult to detach oneself from it, characterises absorption.
Engaged employees show higher levels of energy in, and identification with, their work. These, in turn, have a positive effect on job performance and financial turnover in organisations (Bakker et al., 2008; Bakker \& Demerouti, 2008).

Previous research has consistently shown that job resources, particularly in the midst of elevated job demands, usually drive work engagement (Bakker et al., 2008; Barkhuizen, 2005; Fourie, Rothmann \& Van de Vijver, 2007; Mauno, Kinnunen \& Ruokolainen, 2007; Rothmann \& Jordaan, 2006).

Job resources are the physical, psychological, social or organisational aspects of jobs that reduce job demands, and their associated physiological and psychological costs, or help organisations to achieve their goals and stimulate personal growth, learning and development (Schaufeli \& Bakker, 2004).

According to Bakker and Demerouti (2008), there are resources at the level of the organisation (salary and career opportunities), the level of interpersonal relations (supervisor and coworker support), the level of work organisation (role clarity) or the level of task (task significance and autonomy).

Job resources, like organisational support, growth opportunities and career advancement (Jackson, Rothmann \& Van de Vijver, 2006; Rothmann \& Jordaan, 2006) relate positively to work engagement in the South African context.

\section{The relationship between barriers to change and work engagement}

The availability of job resources is important for shaping perceptions of organisational change (Van Emmerik et al., 2009). One expects that employees with sufficient resources during the change process will be more motivated to do their jobs and be more engaged in their work. In addition, literature on identity also gives a useful insight into the psychological dynamics of organisational change and work engagement.

According to Carr (cited in Smollan \& Sayers, 2009), the processes involved in forming relationships between employees and their organisations are deep-seated, largely unconscious, intimately connected to developing identity and have emotional content.

Therefore, one can see employees' evaluation of change as the set of attitudes about change in their organisations and is a function of the degree to which the changes affect their work (Van Emmerik et al., 2009). Change removes identity and leads to anxiety and grieving (Carr, cited in Smollan \& Sayers, 2009). Kahn (1990) also mentioned that employees' experiences of themselves and their work contexts influence moments of personal engagement and disengagement. Work engagement involves a sense of identification with work (see Bakker et al., 2008). Therefore, barriers to change may have a significant effect on the work engagement of employees.

The researchers used this discussion to formulate the hypothesis that follows: 
- Hypothesis 1: There is no significant relationship between barriers to change and work engagement.

\section{Barriers to change, work engagement and demographic variables}

Given the significance of barriers to change and work engagement to employees and their organisations, it is important to investigate the influence of demographic variables on the two constructs. As far as barriers to change are concerned, the researchers could find very little evidence in the literature that supports a relationship between different demographic variables and barriers to change.

The only related research was that of Coetzee and Stanz (2007). They found that there are no statistically significant differences between barriers to change and demographic variables (business unit, gender, organisational level, length in the organisation, force structure elements, age and language). Other authors indicated that organisational level, tenure, gender, age and home language might have an effect on how people see change (see Coetzee, 2006).

Using this discussion, the researchers formulated this hypothesis:

- Hypothesis 2: There are no significant differences between the barriers to change in employees based on their demographic characteristics (organisational level, tenure, gender, age, language, race and qualification).

With regard to work engagement, researchers have repeatedly found that age and gender affect work engagement (Schaufeli \& Bakker, 2003). The broader picture that emerges is that older employees seemed to be more engaged in their work. Schaufeli, Salanova, González-Romá and Bakker (2002), in a study they did with university students, also found higher levels of engagement amongst older students. With regard to gender, Schaufeli and Bakker (2003) found that women seemed to be less engaged in their jobs than men are. In their study, men scored higher than women did on all three dimensions of work engagement. However, these differences were relatively small and lacked practical significance.

Some South African studies showed that there are significant differences between demographic groups with regard to their qualifications. Jackson and Rothmann (2004) found that schoolteachers with lower qualifications (matriculation and teachers' diplomas) experienced higher levels of vigour and dedication than those with higher qualifications. However, the results were not practically significant because of the small sample.

In addition, Barkhuizen and Rothmann (2006) found that academics with a doctoral qualification were significantly more absorbed in their work than were academics with an honours degree as their highest qualification. In addition, professors were significantly more absorbed in their work than were junior lecturers.
As far as ethnicity is concerned, Segal (2009) found that minority groups (Black people in the United States of America and Indians) reported lower levels of work engagement than did White ethnic groups.

The discussion led to this hypothesis:

- Hypothesis 3: There are significant differences between the work engagement of employees based on their demographic characteristics (organisational level, tenure, gender, age, home language, ethnicity and qualification).

The next sections of the article explain the research design and give the results of the research. The article concludes with a discussion of the research results and makes recommendations for managers and future research into barriers to change and work engagement.

\section{Research design Research approach}

The researchers used a quantitative ex post facto research approach. They used a cross-sectional survey design to collect data and achieve the goals of the research.

This design is ideally suited to the descriptive and predictive functions associated with correlation research and to assessing the interrelationships between the variables in the research (Shaunessey \& Zechmeister, 1997).

\section{Research method Research participants}

The participants were employees of a South African property management company. The researchers distributed 350 questionnaires to a convenience sample of employees who had experienced a merger and acquisition during the previous 18 months. The respondents returned 261 questionnaires. Of these, 234 were suited to statistical analysis. This is a response rate of $75 \%$.

Table 1 gives the demographic characteristics of the participants.

Table 1 indicates that the respondents in this research were primarily female, aged 46 years and older, had English as their home language and were White. Most of the respondents had permanent posts as operational staff, had fewer than two years' experience in the company and had matriculation as their highest qualification.

\section{Measuring instruments}

The researchers administered the Barriers to Change Questionnaire (BCQ) and the Utrecht Work Engagement Scale (UWES) for this research.

The Barriers to Change Questionnaire: The researchers used the BCQ to measure employees' perceptions of barriers to change in the property management organisation (Coetzee, 2006). The BCQ consists of 93 items and measures four dimensions. 
TABLE 1: Biographical details of participants.

\begin{tabular}{|c|c|c|c|}
\hline Item & Category & $F$ & $\%$ \\
\hline Gender & $\begin{array}{l}\text { Male } \\
\text { Female }\end{array}$ & $\begin{array}{c}76 \\
157\end{array}$ & $\begin{array}{l}32.6 \\
67.4\end{array}$ \\
\hline Age & $\begin{array}{l}25 \text { or younger } \\
26-30 \text { years } \\
31-35 \text { years } \\
36-40 \text { years } \\
41-45 \text { years } \\
46 \text { and older }\end{array}$ & $\begin{array}{l}23 \\
43 \\
42 \\
41 \\
40 \\
45\end{array}$ & $\begin{array}{r}9.8 \\
18.4 \\
17.9 \\
17.5 \\
17.1 \\
19.2\end{array}$ \\
\hline Language & $\begin{array}{l}\text { Afrikaans } \\
\text { English } \\
\text { African languages }\end{array}$ & $\begin{array}{c}94 \\
106 \\
34\end{array}$ & $\begin{array}{l}40.2 \\
45.3 \\
14.5\end{array}$ \\
\hline Race & $\begin{array}{l}\text { Asian } \\
\text { Black } \\
\text { Coloured } \\
\text { White }\end{array}$ & $\begin{array}{c}33 \\
40 \\
33 \\
124\end{array}$ & $\begin{array}{l}14.3 \\
17.4 \\
14.3 \\
53.9\end{array}$ \\
\hline Tenure & $\begin{array}{l}\text { Permanent } \\
\text { Temporary or contract }\end{array}$ & $\begin{array}{c}223 \\
10\end{array}$ & $\begin{array}{r}95.7 \\
4.3\end{array}$ \\
\hline $\begin{array}{l}\text { Organisational } \\
\text { level }\end{array}$ & $\begin{array}{l}\text { Executive committee } \\
\text { Senior management } \\
\text { Middle management } \\
\text { Supervisory or junior management } \\
\text { Operational staff }\end{array}$ & $\begin{array}{c}8 \\
4 \\
55 \\
45 \\
112\end{array}$ & $\begin{array}{r}3.6 \\
1.8 \\
24.6 \\
20.1 \\
50.0\end{array}$ \\
\hline Years employed & $\begin{array}{l}\text { Fewer than two years } \\
2-5 \text { years } \\
6-10 \text { years } \\
11-15 \text { years } \\
16 \text { years or more }\end{array}$ & $\begin{array}{c}102 \\
55 \\
22 \\
16 \\
38\end{array}$ & $\begin{array}{r}43.8 \\
23.6 \\
9.4 \\
6.9 \\
16.3\end{array}$ \\
\hline Qualification & $\begin{array}{l}\text { Lower than matriculation } \\
\text { Matriculation } \\
\text { Diploma } \\
\text { Degree } \\
\text { Post-graduate degree }\end{array}$ & $\begin{array}{l}23 \\
88 \\
81 \\
19 \\
21\end{array}$ & $\begin{array}{r}9.9 \\
37.9 \\
34.9 \\
8.2 \\
9.1\end{array}$ \\
\hline
\end{tabular}

$F$, frequency.

The project-related barriers comprise 16 items. An example is 'To what extent is the change project on time?' The peoplerelated barriers comprise 36 items, an example of which is 'To what extent do you believe that you have the ability to change?' The organisation-related barriers comprise 39 items and an example is 'To what extent do you receive recognition for the work you do?' Finally, the environment-related barriers comprise only two items. One example is 'To what extent do suppliers and customers support the change that the company is going through?'

The researchers measured the responses to the 93 items using a 6-point scale. It ranges from 1 ('embraces nothing') to 6 ('embraces many measures').

They found acceptable internal consistencies for the four dimensions. They ranged from 0.84 to 0.97 (Coetzee, 2006).

The Utrecht Work Engagement Scale: The researchers used the UWES questionnaire (Schaufeli et al., 2002) to measure the vigour, dedication and absorption dimensions of work engagement.

Six items measure vigour. An example is 'I am bursting with energy in my work'. Another five items measure dedication, of which 'I find my work full of meaning and purpose' is an example. Six items measure absorption. An example is 'When I am working, I forget everything else around me'. High levels of vigour, dedication and absorption characterise engaged workers.

Researchers have used the UWES extensively in South African research. With regard to internal consistency, reliability coefficients for the three subscales fall between 0.68 and 0.91 (see Barkhuizen \& Rothmann, 2006; Jackson \& Rothmann, 2004; Naudé \& Rothmann, 2004).

Demographic information the researchers gathered included information about the characteristics of the participants. They included organisational level, basis of employment, gender, age, home language, ethnicity and qualification.

\section{Research procedure}

The researchers obtained permission from the top managers of each region and unit to conduct the research. They explained the purpose of the research clearly to unit managers and participants. The researchers distributed the surveys manually to the research participants and collected the completed surveys. They explained the purpose and procedure of the research to all the participants. Participation was voluntary. The researchers respected the privacy of the participants and kept the information they collected confidential and anonymous at all times.

\section{Statistical analysis}

The researchers performed the statistical analysis using the SPSS 17.0 for Windows Program (SPSS Inc., 2009). They determined the reliability and validity of the BCQ and UWES using Cronbach alpha coefficients and exploratory factor analysis.

The researchers used Pearson product-moment correlation coefficients to determine the relationships between barriers to change and work engagement. They set a cut-off point of 0.30 (medium effect, Cohen, 1988) for the practical significance of the correlation coefficients.

The researchers used multivariate analyses of variance (MANOVA) to determine the significance of the differences between the levels of barriers to change and work engagement of the demographic groups.

When an effect is significant in MANOVA, one uses ANOVA to discover which dependent variables are affected. A 95\% confidence interval level $(p \leq 0.05)$ is statistically significant. The researchers used effect sizes (Steyn, 1999) to decide on the practical significance of the findings.

\section{Results}

Before testing their hypotheses, the researchers examined the psychometric properties of the Barriers to Change Questionnaire (BCQ) and Utrecht Work Engagement Scale (UWES). They performed this using the Kaiser-Meyer-Olkin (KMO) to determine the sample adequacy and sphericity of the item-correlation matrix, an exploratory factor analysis to discover and identify the dimensions of the measurements and a reliability analysis, using Cronbach alpha coefficients, to determine the accuracy of the instruments and to see whether the results are repeatable. 
The BCQ and UWES yielded a measure of sampling adequacy of 0.876 and 0.919 respectively. This, according to the guideline of $>0.60$, is adequate for factor analysis (Hair, Anderson, Tatham \& Black, 1998).

The researchers performed exploratory factor analyses using the principal axis factoring extraction method on the BCQ and UWES. The results revealed one underlying factor for both the BCQ and UWES. They labelled the BCQ factor 'barriers to change' and UWES factor 'work engagement'.

Table 2 gives the descriptive statistics and reliabilities of the BCQ and UWES.

Table 2 shows that barriers to change and work engagement, as well as their dimensions, have a normal distribution. They also show low skewness and kurtosis.

The Cronbach alpha coefficients compare well with the guideline of 0.70 . Therefore, the internal consistency of the dimensions explains a large percentage of the variance (Nunnally \& Bernstein, 1994).

From the mean scores of the $\mathrm{BCQ}$, it is clear that the participants perceived average to low level of barriers to change: the closer the mean score is to 1 , the higher is the level of barriers to change and vice versa. In addition, participants showed average levels of work engagement.

\section{Testing the hypotheses}

The researchers used Pearson correlations to test for the significance of the relationship between barriers to change and work engagement. Firstly, they performed a correlation analysis between the one-factor variable of barriers to change (the independent variable) and work engagement (the dependent variable).

Table 3 gives the results.

Table 3 shows a practically significant relationship between barriers to change and work engagement $\left(r_{(d f=225 ; p<0.001)}=0.519\right.$, a large effect $)$.

The researchers then computed Pearson correlations to test for the significance of the relationships between the dimensions of barriers to change and work engagement.

Table 4 gives the results.

Table 4 shows that:

- the project-related barriers have practically significantly relationships with vigour, dedication and absorption (all medium effects)

- the people-related barriers have practically significantly relationships with vigour, dedication and absorption (all medium effects)

- the organisational barriers have practically significantly
TABLE 2: Descriptive statistics and alpha coefficients for the Barriers to Change Questionnaire and the Utrecht Work Engagement Scale.

\begin{tabular}{lccccc}
\hline Scales & Mean & SD & Skewness & Kurtosis & $\boldsymbol{\alpha}$ \\
\hline $\begin{array}{l}\text { 1. Barriers to change } \\
\text { Subscales }\end{array}$ & 3.699 & 1.400 & 0.072 & 0.061 & 0.97 \\
Project barriers & & & & & \\
People barriers & 3.255 & 1.414 & -0.018 & 0.145 & 0.926 \\
Organisation barriers & 3.767 & 1.433 & 0.052 & -0.315 & 0.909 \\
Environment barriers & 3.846 & 1.359 & -0.003 & 0.388 & 0.959 \\
2. Work engagement & 3.130 & 1.486 & 0.012 & -0.052 & 0.864 \\
Subscales & 3.914 & 1.340 & -0.384 & 0.160 & 0.916 \\
Vigour & & & & & \\
Dedication & 4.147 & 1.279 & -0.224 & 0.098 & 0.783 \\
Absorption & 4.372 & 1.343 & -0.582 & 0.479 & 0.857 \\
\hline
\end{tabular}

SD, standard deviation.

$\alpha$, Cronbach Alpha.

TABLE 3: Correlation coefficient between barriers to change and work engagement

\begin{tabular}{lccc}
\hline Correlation coefficients & \multicolumn{3}{c}{ Work engagement } \\
\cline { 2 - 4 } & $\begin{array}{c}\text { Pearson } \\
\text { correlation }\end{array}$ & $\begin{array}{c}\text { Sig. } \\
\text { (2-tailed) }\end{array}$ & $N$ \\
\hline Barriers to change & $0.519^{* *}$ & $0.000^{*}$ & 225
\end{tabular}

Sig., significance.

$N$ denotes numbe

${ }^{*}$, statistical significance at $p>0.01 ; * *$, practically significant correlation (large effect) $r>0.50$

TABLE 4: Correlation coefficients between barriers to change dimensions and work engagement dimensions.

\begin{tabular}{lccc}
\hline Pearson correlation & Vigour & Dedication & Absorption \\
\hline Project barriers & $0.355^{*} \dagger$ & $0.400^{*} \dagger$ & $0.391^{*} \dagger$ \\
People barriers & $0.450^{*} \dagger$ & $0.415^{*} \dagger$ & $0.488^{*} \dagger$ \\
Organisation barriers & $0.408^{* \dagger}$ & $0.454^{*} \dagger$ & $0.427^{* \dagger}$ \\
Environment barriers & $0.258^{*}$ & $0.228^{* *}$ & $0.280^{* *}$ \\
\hline
\end{tabular}

$\dagger$, A practically significant correlation (medium effect): $r>0.30$.

${ }^{*}$, statistical significance at $p>0.01 ;{ }^{* *}$, practically significant correlation.

relationships with vigour, dedication and absorption (all medium effects)

- the environment-related barriers have practically significantly relationships with vigour, dedication and absorption (all low effects).

Therefore, the researchers reject Hypothesis 1.

\section{Relationship between barriers to change and demographic variables}

The researchers then conducted MANOVA analyses to assess the relationships between the BCQ dimensions and the demographic variables of age, race or ethnicity, gender, language, marital status, seniority level, qualification, professional level, years in position and years of experience.

Firstly, the researchers tested the results for significance using Wilk's Lambda. They used Cohen's (1988) classification of effect sizes, where 0.01 is small, 0.09 is medium and 0.25 is large, to indicate the magnitude of a finding.

Table 5 gives the results of the significant relationships between barriers to change and background variable dimensions. 
Table 5 shows that there are significant differences between groupings according to home language, ethnicity, job level and the BCQ dimensions. The results show no significant differences between groupings according to age, gender, tenure, years of service in the company and qualification.

The researchers analysed the results of the significant relationships further. They appear below.

The Wilks Lambda for home language equals $0.926[F(8,448)$ $=2.197, p \leq 0.05]$. The analysis of each dependent variable, using a Bonferroni adjusted alpha level of 0.025 , showed that the ethnic groups differed in:

- project-related barriers $\left(F_{(2,227)}=6.042, p \leq 0.05\right.$, partial $\left.\eta^{2}=0.051\right)$

- people-related barriers $\left(F_{(2,227)}=3.029, p \leq 0.05\right.$, partial $\left.\eta^{2}=0.026\right)$

- organisation-related barriers $\left(F_{(2,227)}=3.898, p \leq 0.05\right.$, partial $\eta^{2}=0.033$ )

- environment-related barriers $\left(F_{(2,227)}=6.090, p \leq 0.05\right.$, partial $\left.\eta^{2}=0.051\right)$.

Employees with Afrikaans as their home language experienced fewer project-related, people-related, organisation-related and environment-related barriers than did employees with English as their home language. The effects were small.

The Wilks Lambda for ethnicity equals $0.871[F(12,348)$ $=2.594, p \leq 0.05]$. The analysis of each dependent variable, using a Bonferroni adjusted alpha level of 0.025, showed that the ethnic groups differed in:

- project-related barriers $\left(F_{(3,222)}=5.973, p \leq 0.05\right.$, partial $\left.\eta^{2}=0.075\right)$
- people-related barriers $\left(F_{(3,222)}=4.724, p \leq 0.05\right.$, partial $\left.\eta^{2}=0.060\right)$

- organisation-related barriers $\left(F_{(3,222)}=6.750, p \leq 0.05\right.$, partial $\left.\eta^{2}=0.084\right)$.

The White ethnic groups experienced fewer people-related, project-related and organisation-related barriers than did the Asian and Coloured ethnic groups. The effects were small. The White ethnic groups experienced fewer people-related barriers than did the Coloured ethnic groups (a small effect). In addition, the White and Black ethnic groups experienced fewer organisation-related barriers than did the Coloured ethnic groups (all small effects).

The Wilks Lambda for job level equals $0.886[F(16,651.363)$ $=1.649, p \leq 0.05]$. The analysis of each dependent variable, using a Bonferroni adjusted alpha level of 0.025, showed that groups differed in environment-related barriers $\left(F_{(4,216)}=2.585, p \leq 0.05\right.$, partial $\left.\eta^{2}=0.046\right)$. Operational staff experienced more environment-related barriers than did middle managers. However, the effect was small.

Therefore, the researchers partially accepted Hypothesis 2.

\section{Relationship between work engagement and demographic variables}

The researchers then performed MANOVA analyses to assess the relationships between the work engagement dimensions and the demographic variables of age, race or ethnicity, gender, language, marital status, seniority level, qualification, professional level, years in position and years of experience. Table 6 gives the results.

TABLE 5: Manova for barriers to change and the demographic variables.

\begin{tabular}{|c|c|c|c|c|c|c|}
\hline \multirow[t]{2}{*}{ Item } & \multirow[t]{2}{*}{ Value } & \multirow[t]{2}{*}{$F$} & \multicolumn{2}{|c|}{$d f$} & \multirow[t]{2}{*}{ Sig. } & \multirow{2}{*}{$\begin{array}{l}\text { Partial Eta } \\
\text { Squared }\end{array}$} \\
\hline & & & Hypothesis & Error & & \\
\hline Age & 0.871 & 1.559 & 20.000 & 733.924 & 0.057 & 0.034 \\
\hline Gender & 0.983 & $0.945^{\mathrm{a}}$ & 4.000 & 224.000 & 0.439 & 0.017 \\
\hline Language & 0.926 & $2.197^{\mathrm{a}}$ & 8.000 & 448.000 & 0.027 & $0.038^{*}$ \\
\hline Ethnicity & 0.871 & 2.594 & 12.000 & 579.711 & 0.002 & $0.045^{*}$ \\
\hline Tenure & 0.980 & $1.150^{\mathrm{a}}$ & 4.000 & 224.000 & 0.334 & 0.020 \\
\hline Job level & 0.886 & 1.649 & 16.000 & 651.363 & 0.052 & $0.030^{*}$ \\
\hline Years in company & 0.944 & 0.800 & 16.000 & 675.804 & 0.686 & 0.014 \\
\hline Education & 0.962 & 0.710 & 12.000 & 585.003 & 0.743 & 0.013 \\
\hline
\end{tabular}

$d f$, degrees of freedom; Sig, significance; $F$, frequency.

a, A Bonferroni adjusted alpha level of 0.025 was used.

*, significance at $p \leq 0.05$

TABLE 6: Manova for work engagement and demographic variable.

\begin{tabular}{|c|c|c|c|c|c|c|}
\hline \multirow[t]{2}{*}{ Variable } & \multirow[t]{2}{*}{ Value } & \multirow[t]{2}{*}{$F$} & \multicolumn{2}{|c|}{$d f$} & \multirow[t]{2}{*}{ Sig. } & \multirow[t]{2}{*}{ Partial Eta Squared } \\
\hline & & & Hypothesis & Error & & \\
\hline Age & 0.922 & 1.203 & 15.000 & 607.725 & 0.264 & 0.027 \\
\hline Gender & 0.977 & $1.758^{\mathrm{a}}$ & 3.000 & 223.000 & 0.156 & 0.023 \\
\hline Home language & 0.946 & $2.103^{\mathrm{a}}$ & 6.000 & 446.000 & 0.052 & $0.028^{*}$ \\
\hline Ethnicity & 0.899 & 2.627 & 9.000 & 530.705 & 0.006 & $0.035^{*}$ \\
\hline Tenure & 0.993 & $0.489^{\mathrm{a}}$ & 3.000 & 223.000 & 0.690 & 0.007 \\
\hline Job level & 0.963 & 0.673 & 12.000 & 561.191 & 0.778 & 0.013 \\
\hline Years in company & 0.924 & 1.464 & 12.000 & 582.357 & 0.133 & 0.026 \\
\hline Qualification & 0.862 & 2.227 & 15.000 & 602.203 & 0.005 & $0.048^{*}$ \\
\hline
\end{tabular}

$d f$, degrees of freedom; Sig, significance; F, frequency.

, A Bonferroni adjusted alpha level of 0.025 was used

$*$, at $p \leq 0.05$ 
Table 6 shows that there are only significant differences, in work engagement dimensions, between groupings according to home language, ethnicity and qualification. The results show no statistically significant differences between groupings according to gender, organisational level, number of years in the position and years of work experience.

The results of the significant relationships between the background variables and work engagement dimensions follow.

The Wilks Lambda for home language equals 0.946 $[F(6,466)=2.103, p \leq 0.05]$. The analysis of each dependent variable, usingaBonferroniadjustedalphalevelof 0.025 , showed that the ethnic groups differed in:

- $\operatorname{vigour}\left(F_{(2,225)}=3.154, p \leq 0.05\right.$, partial $\left.\eta^{2}=0.027\right)$

- dedication $\left(F_{(2,225)}=4.252, p \leq 0.5\right.$, partial $\left.\eta^{2}=0.036\right)$

- $\operatorname{absorption}\left(F_{(2,225)}=4.391, p \leq 0.05\right.$, partial $\left.\eta^{2}=0.038\right)$.

Employees with Afrikaans as home language reported higher levels of vigour, dedication and absorption than did employees with English as their home language. However, the effects were small.

The Wilks Lambda for ethnicity equals 0.899 $[F(9,220)=2.627, p \leq 0.05]$. The analysis of each dependent variable, using a Bonferroni adjusted alpha level of 0.025 , showed that the ethnic groups differed in:

- $\operatorname{vigour}\left(F_{(3,220)}=5.774, p \leq 0.05\right.$, partial $\left.\eta^{2}=0.073\right)$

- dedication $\left(F_{(3,220)}=3.865, p \leq 0.05\right.$, partial $\left.\eta^{2}=0.050\right)$

- absorption $\left(F_{(3,220)}=4.928, p \leq 0.05\right.$, partial $\left.\eta^{2}=0.063\right)$.

White ethnic groups reported higher levels of vigour, dedication and absorption than Coloured ethnic groups did and higher levels of absorption than Black ethnic groups did. However, the effects were small.

The Wilks Lambda for qualification equals 0.862 $[F(15,220)=2.227, p \leq 0.05]$. The analysis of each dependent variable, using a Bonferroni adjusted alpha level of 0.025 , showed that the employees grouped according to qualification differed in absorption $\left(F_{(5,220)}=2.940\right.$, $p \leq 0.05$, partial $\left.\eta^{2}=0.063\right)$. Employees with matriculation as a qualification reported higher levels of absorption in their work than employees with a post-graduate qualification did. However, the effect was small. Therefore, the researchers partially accepted Hypothesis 3.

\section{Discussion}

The main objective of this research was to determine the relationships between the barriers to change and work engagement of employees in a South African property management company. In addition, the research sought to determine whether there are statistically significant differences between the different groups with regard to barriers to change and work engagement according to demographic variables.
The research makes an important contribution to understanding the extent to which barriers to change affect work engagement. Therefore, the research assists organisations to identify the work environments and jobs that accept organisational change. They can be useful in eliminating the negative effects of change.

The researchers discuss the results of the research in terms of the hypotheses:

- Hypothesis 1: There is no significant relationship between barriers to change and work engagement.

The results showed that, in general, the barriers to change had a practically significant relationship with work engagement, with a large effect.

The dimensions of barriers to change (the project-related, people-related and organisation-related barriers) had a practically significant relationship with the dimensions of work engagement (vigour, dedication and absorption), with a medium effect.

Environmental barriers had a statistically significant relationship with the work engagement dimensions, with a low effect. The relationships were all positive.

One possible explanation is that employees in this company did not experience high levels of barriers to change. The mean scores show this. Therefore, they indicated a positive relationship with work engagement.

Another possible explanation comes from the Comprehensive Burnout and Engagement (COBE) model of Schaufeli and Bakker (2003). They found that job resources were predictors of work engagement (see Bakker et al., 2008; Mauno et al., 2007; Rothmann \& Jordaan, 2006; Schaufeli \& Bakker, 2004). Project-related and people-related barriers in this context relate closely to a lack of job resources (physical, psychological and/or organisational). Therefore, they may have a positive relationship with work engagement. However, we need more research to investigate the relationships between the two dimensions:

- Hypothesis 2: There is no significant relationship between barriers to change and demographic variables.

The researchers found significant relationships between the different demographic groupings (according to home language, ethnicity and job levels) and barriers to change. The results contradict the results that Coetzee and Stanz (2007) obtained. They found no significant relationships between demographic groups and barriers to change.

This research showed that employees with Afrikaans as their home language experienced fewer project-related, people-related, organisation-related and environmentrelated barriers than did employees with English as their home language. Furthermore, White ethnic groups 
experienced fewer people-related, project-related and organisation-related barriers than Asian and Coloured ethnic groups did. In addition, Black ethnic groups experienced fewer organisation-related barriers than Coloured ethnic groups did.

According to Steward (cited in Coetzee, 2006), a failure to understand people with differing backgrounds and experience may create barriers to communication. The more widely those backgrounds differ, the greater the risk is of misunderstanding.

The results also showed that operational staff experienced more environmental barriers to change than did employees in middle management. According to Young (in Coetzee, 2006), middle managers respond to changing environments in their own distinctive ways. In addition, operational staff members interact more frequently with customers and clients than middle managers do. Therefore, operational staff members may be more prone to the effects of the customers, or clients, experiences of changes in organisations.

Therefore, we need more research to explore the relationships between demographic variables and barriers to change:

- Hypothesis 3: There is a significant relationship between work engagement and demographic variables.

The results showed that there are significant differences between demographic groupings based on home language, ethnicity, qualification and the work engagement of those groups.

Employees with Afrikaans as their home language reported higher levels of vigour, dedication and absorption than did employees with English as their home language. One possible explanation is that Afrikaans-speaking employees reported lower levels of barriers to change than Englishspeaking employees did. Therefore, they reported higher levels of work engagement.

White ethnic groups reported higher levels of vigour, dedication and absorption than Coloured ethnic groups and higher levels of absorption than Black ethnic groups did. One may attribute this to the fact that most of the White ethnic group was Afrikaans-speaking and reported higher levels of work engagement.

Finding new and alternative pathways (hope), prior confidence (efficacy), combined with prior optimism and new resilience and the ability to achieve personal objectives in the midst of change, could explain the results of the White ethnic group (Grobbelaar, 2007).

One can ascribe the results of the Coloured ethnic groups to the perception that minority groups still experience less fairness and development opportunities in organisations (see Segal, 2009). However, we need more research to verify these results.

Employees with matriculation as their highest qualification reported higher levels of absorption in their work than employees with a post-graduate qualification did.

The results partially confirm the results of previous research that Jackson and Rothmann (2004) conducted. It showed that teachers with lower qualifications tended to be more engaged as far as the vigour and dedication dimensions are concerned. However, one should note that only $21.15 \%$ of the sample had a teacher's diploma, an honours (18.51\%) or master's $(2.64 \%)$ degree. The small sizes of the latter groups could explain that the differences were not practically significant. However, the results contradict the findings of Barkhuizen and Rothmann (2006). They found that academics with a doctoral degree tended to be more absorbed in their work than did those with a four-year or honours degree.

\section{Implications for practice}

The research showed that barriers to change have a significant effect on the work engagement of the employees. Therefore, managers should eliminate project-barriers, people-barriers, organisational-barriers and environmentalbarriers proactively because they can have an adverse effect on employees.

In addition, the research can assist managers to design and implement effective change interventions and improve the chances of successful change.

Finally, organisations and organisational development specialists can use the additional knowledge the researchers gained about the relationships between barriers to change and work engagement to improve their current change processes.

\section{Limitations of the research}

A significant limitation of this research was the shortage of literature and empirical research on barriers to change. This made it difficult to interpret the findings.

We need more research to develop a theory about barriers to change in organisations.

A second limitation was the size of the sample and the sampling procedure the researchers used in the present study. It prevents generalising the findings to the whole population.

Future studies could benefit from a stratified random sample. This would ensure sufficient representation of the different groups in property management organisations. 
Future studies should also focus on longitudinal studies. They could determine the causes and effects of barriers to change and work engagement.

\section{Recommendations}

There should be more studies using the same research tools (BCQ and UWES) to generalise findings. The sample should include other property management organisations to generalise findings.

A suggestion that may improve the methodology the researchers used is that the BCQ questionnaire should include a 'Do not know' option.

Coetzee and Stanz (2007) made the same suggestion about the 6-point Likert-response scale. It will improve the reliability and validity of the responses. The reason for this suggestion is that, at certain organisational levels, respondents will not know the answers because of the nature of the questions. An example is 'To what extent is the change project within budget?' At lower organisational levels, it is impossible for respondents to know whether the project is within budget.

Further research could be conducted to develop more questions that fall within 'The environmental barriers to change' dimension.

\section{Conclusions}

A holistic approach to change management is necessary. It is imperative that organisations help people to see or feel problems. Solutions or progress will influence their emotions. These, in turn, will improve their commitment to behavioural change or reinforce change behaviour.

The study of the relationship between barriers to change and work engagement is a new field and there are many gaps in the body of knowledge.

Barriers to change, work engagement, resistance to change and change management are all-embracing and versatile concepts that diverse dimensions and viewpoints characterise. They infuse all parts of organisational existence and have become a trendy field of study because of the promises they hold for continuous organisational survival and improving organisational performance.

The importance of managing barriers to change and work engagement is a strategic issue that we cannot underestimate. Organisations that ignore it and simply add it to their list of people-related issues will regret the results of their judgement.

On the other hand, organisations who realise its implications and significance will find that change will become easier and that their workforce becomes more engaged.

\section{Acknowledgements}

The authors would like acknowledge and give a special word of thanks to Prof. Karel Stanz who gave permission to use the Barriers to Change Questionnaire.

\section{Authors' contributions}

This article is part of E.B.'s research for a master's degree. N.B. was the supervisor. Both authors contributed to the research for the article.

\section{Author competing interests}

The authors declare that they have no financial or personal relationship(s) which may have inappropriately influenced them in writing this paper.

\section{References}

Bakker, A.B., \& Demerouti, E. (2008). Towards a model of work engagement. Career Development International, 13(3), 209-223. doi:10.1108/13620430810870476

Bakker, A.B., Schaufeli, W.B., Leiter, M.P., \& Taris, T.W. (2008). Work engagement: An emerging concept in occupational psychology. Work \& Stress, 22(3), 187-200. doi:10.1080/02678370802393649

Barkhuizen, E.N. (2005). Work wellness of academic staff in higher education institutions. Unpublished doctoral thesis. North-West University, Potchefstroom, South Africa.

Barkhuizen, E.N., \& Rothmann, S. (2006). Work engagement of academic staff in South African higher education institutions. Management Dynamics, 15(1), 38-48.

Coetzee, C.J.H. (2006). 'Barriers-to-Change' in a Governmental service delivery type of organisation. Unpublished doctoral thesis. University of Johannesburg, Johannesburg, South Africa.

Coetzee, C.J.H., \& Stanz, K.J. (2007). 'Barriers-to-Change' in a Governmental service delivery type of organisation. South African Journal of Human Resource Management, 33(2), 76-82.

Cohen, J. (1988). Statistical power analysis for the behavioral sciences. (rev. edn.). Orlando, FL: Academic Press.

Fourie, L., Rothmann, S., \& Van de Vijver, F. (2007). A model of work wellness for nonprofessional counsellors in South Africa. Stress \& Health, 24, 35-47. doi:10.1002/ smi.1163

Goleman, D., Boyatzis, R., \& McKee, A. (2002). Primal Leadership: Realizing the power of emotional intelligence. Boston, MA: Harvard Business School Press.

Grimm, L.G., \& Yarnould, P.R. (2006). Reading and understanding multivariate statistics. (11th edn.). Washington, DC: American Psychological Association.

Grobbelaar, B. (2007). Positive Organisational Behaviour in the South African context Unpublished masters dissertation.: University of Pretoria, Pretoria, South Africa.

Hair, J.F. Jr., Anderson, R.E., Tatham, R.L., \& Black, W.C. (1998). Multivariate Data Analysis. (5th edn.). Upper Saddle River, NJ: Prentice-Hall International.

Harich, J. (2010). Change resistance as the crux of the environmental sustainability problem. Systems Dynamics Review, 26(1), 35-72.

Higgs, M. (2002). An exploration of the relationship between emotional intelligence and leadership potential. Journal of Managerial Psychology, 18(8), 814-823. doi:10.1108/02683940310511890

Isern, J., \& Pung, C. (2007). Harnessing energy to drive organisational change. McKinsey Quarterly, 1, 1-4.

Jackson, L.T.B., \& Rothmann, S. (2004). Burnout and work engagement of South African school teachers. Unpublished doctoral thesis. North-West University. Potchefstroom, South Africa.

Jackson, L.T.B., Rothmann, S., \& Van de Vijver, F. (2006). A model of work-related wellbeing for educators in South Africa. Stress \& Health, 22, 263-274. doi:10.1002/ smi.1098

Kahn, W.A. (1990). Psychological conditions of personal engagement and disengagement at work. Academy of Management Journal, 33, 692-724. doi:10.2307/256287

Lombard, C.N., \& Crafford, A. (2003). Competency requirements for first-line managers to deal with resistance to change. South African Journal of Human Resource Management, 1(1), 42-52.

Mason, R.B. (2008). Management actions, attitudes to change and perceptions of the external environment: A Complexity theory approach. Journal of General Management, 34(1), 37-53.

Mauno, S., Kinnunen, U., \& Ruokolainen, M. (2007). Job demands and resources as antecedents of work engagement: A Longitudinal Study. Department of Psychology, University of Jyvaskla. Finland: University of Tampere. 
Msweli-Mbanga, P., \& Potwana, N. (2006). Modelling participation, resistance to change and organisational citizenship behaviour: A South African case. South African Journal of Business Management, 37(1), 21-29.

Ndlovu, N., \& Parumasur, S.B. (2005, March). The perceived impact of downsizing and organizational transformational survivors. Paper presented at the Changing World of Work Conference, Vanderbijlpark, South Africa.

Naude, J.L.P., \& Rothmann, S. (2004). The validation of the Utrecht Work Engagement Scale for Emergency Medical Technicians in Gauteng. South African Journal of Economic and Management Sciences, 3, 459-468.

Nunnally, J.C., \& Bernstein, I.H. (1994). Psychometric theory. (3rd edn.). New York: McGraw-Hill.

Oreg, S. (2006). Personality, context, and resistance to organisational change European Journal of Work and Organisational Psychology, 15(1), 73-101. doi:10.1080/13594320500451247

Rothmann, S., \& Jordaan, G.M.E. (2006). Job demands, job resources and work engagement of academic staff in South African higher education institutions. South African Journal of Industrial Psychology, 32(4), 87-96.

Rees, C. (1997). Empowerment: theory and practice. Retrieved November 03, 2008 from http://www.emeraldinsight.com

Schaufeli, W.B., \& Bakker, A.B. (2001). Work and well-being: Towards a positive approach to occupational and health psychology. Journal of Organisational Behavior, 14, 229-253.

Schaufeli, W.B., \& Bakker, A.B. (2003). The role of self-efficacy in performing emotional work. Journal of Vocational Behavior, 69(2), 222-235.

Schaufeli, W.B., \& Bakker, A.B. (2004). Job demands, job resources, and their relationship with burnout and engagement: A multi-sample study. Journal of Organizational Behavior, 25, 293-315. doi:10.1002/job.248

Schaufeli, W.B., Salanova, M., González-Romá, V., \& Bakker, A.B. (2002). The measurement of engagement and burnout: $A$ confirmative analytic approach. Journal of Happiness Studies, 3, 71-92.
Segal, B. (2009). Employee Engagement masks real differences in work attitudes between whites and minorities. New York: Sirota Survey Intelligence.

Shaughnessy, J.J., \& Zechmeister, E.B. (1997). Research methods in psychology. (4th edn.). New York: McGraw-Hill.

Smythe, J. (2005). The democratization of strategy and change: Headlines from a recent study into employee engagement. Communication World, 1, 32-35.

Smollan, R.K., \& Sayers, J.G. (2009). Organisational Culture, Change and Emotions: A Qualitative study. Journal of Change Management, 9, 435-457. doi:10.1080/14697010903360632

Soltani, E., Lai, P., \& Mahmoudi, V. (2007). Managing change initiatives: Fantasy or Reality? The case of public sector organisations. Total Quality Management, 18(1-2), 153-179.

SPSS 17.0 for Windows. [Computer software] (2009). Chicago, IL: SPPS Inc.

Steyn, H.S. (1999). Praktiese betekenisvolheid: Die gebruik van effekgroottes. [Practical significance: The use of effect sizes]. Wetenskaplike bydraes - Reeks B: Natuurwetenskappe Nr. 117. Potchefstroom: PU vir CHO.

The Institute of Corporate Productivity. (2009, 14 November). Survey results April 2008: Organisations worldwide on managing change. Message emailed to researcher, archived at www.i4cp.com

US Industry Report (2011). Property Management. Retrieved n.d., from http://www. ibisworld.com/industry/default.aspx?indid=1356

Van Emmerik, I.J.H., Bakker, A., \& Euwema, M.C. (2009). Explaining employees' evaluations of organisational change with the job-demands resources model. Career Development International, 14(6), 594-613. doi:10.1108/13620430910997312

Williams, K., Crafford, A., \& Fourie, L. (2003). An exploration of individual experiences of constant organisational change. South African Journal of Industrial Psychology, 29(2), 98-105. 